\title{
A constituição do Sistema Financeiro Imobiliário (SFI) e o direito à moradia: matriz teórica e seu contexto histórico.
}

\section{Brenda Alves Ribeiro*, Mariana Azevedo Barretto Fix.}

\section{Resumo}

O objetivo deste trabalho é discutir a matriz teórica que justifica a constituição do Sistema Financeiro Imobiliário (SFI) no Brasil. Assim, realizou-se uma revisão histórica de como as políticas públicas que dizem respeito à habitação se formaram no Brasil, a fim de entender a formação das relações entre Estado, população e agentes privados ao longo do tempo. Depois, retoma-se também a ascensão do neoliberalismo no mundo desde os anos 1970 e 1980, bem como o discurso hegemônico dos formuladores de políticas públicas dos países centrais, que trazem como máxima a redução do Estado e a necessidade de atender às necessidades básicas através do mercado. Finalmente, iniciou-se uma análise do discurso dos documentos relativos à fundação do SFI, a partir de uma abordagem histórica que considera a fundação deste sistema dentro de um contexto de mudança de paradigma de desenvolvimento no neoliberalismo, que se dá partir dos países centrais. Ao final, compara-se o discurso e a prática deste sistema, considerando a trajetória histórica do país e as relações deste com esse novo paradigma, dado o cenário de um país subdesenvolvido.

\section{Palavras-chave:}

Sistema Financeiro Imobiliário, Direito à moradia, Financeirização

\section{Introdução}

Inspirado no modelo estadunidense, o SFI nasce em 1997, a partir de projetos do setor de crédito imobiliário que datam do início dos anos 1990. Em um contexto de abertura neoliberal, sua proposta é permitir o aumento do acesso ao direito à moradia através da aquisição de imóveis via crédito privado, sem que haja necessidade de intervenção ou financiamento do Estado. A partir da análise de documentos da fundação do SFI, busca-se entender o discurso que sustentou a criação desse sistema, com enfoque especial para a questão da redução do papel do Estado e a defesa da desregulação do marco regulatório e do mercado de capitais, bem como as contradições deste discurso.

\section{Resultados e Discussão}

A partir da categorização de Marta Arretche (1990) ', tem-se que consolidação de políticas públicas para habitação no Brasil se dá conforme o modelo "estatalprivatista". Ou seja, ainda que o Estado tenha sido um ator fundamental ao longo do século XX para provisão de habitação, este tem dificuldade de encarar habitação popular como item do desenvolvimento social e como "bem público" a ser provido pelo Estado mediante o uso dos recursos tributários. As políticas habitacionais se consolidaram segundo a lógica da empresa privada, buscando a autossustentação financeira. Assim, a notória transformação do aparato produtivo não foi acompanhada por garantia de direitos sociais pelo Estado a todas as camadas, mantendo o perfil de cidadania regulada que permeia todas as políticas públicas do período. A habitação, no final de contas, é tratada como mercadoria e não como direito.

Com a fase de expansão financeira do sistema mundial, a crise fiscal e a insuficiência dos fundos administrados pelo Estado a partir da crise econômicofinanceira da década de 1970, tem-se a transformação do papel dos Governos: de provedores de políticas sociais à "facilitadores", cuja missão é abrir espaço e apoiar a expansão dos mercados privados. A fundação do SFI é um marco institucional de consolidação destes ideais no Brasil, uma vez que essas que já norteavam políticas habitacionais na Europa e nos Estados Unidos desde a década de 80 .

Inspirado no modelo europeu neoliberal, o discurso dos formuladores tem como objetivo primordial a desoneração do Estado, bem como a habitação como pretexto para a fundação do sistema. Baseado em Luciana Royer (2011) 2, mostra-se que tais argumentos são falaciosos, uma vez que o sistema vislumbra acessar os recursos do fundo público para mercado secundário e propulsão do crédito imobiliário, a fim de financiar o mercado imobiliário especulativo, não atrelado a habitação. Além disso, promove-se a abertura ao mercado externo e conexão com fluxos internacionais, a fim de favorecer o mercado de capitais, bem como a consolidação de um projeto de Estado que desconsidera seu papel redistributivo. O sistema, assim, promove uma política apenas teoricamente habitacional totalmente desconectada do direito à moradia.

\section{Conclusões}

O SFI é uma ilustração clara de como há uma mudança de paradigma de desenvolvimento e modelo de Estado no país após a crise da dívida. No entanto, devido ao caráter estatal-privatista que permeia a história das políticas habitacionais, não é inédito o tratamento da moradia como mercadoria que a imposição do neoliberalismo traz. Assim, as políticas habitacionais no Brasil sinalizam que o avanço do neoliberalismo tem pressupostos e consequências diferentes de que nos países subdesenvolvidos.

\section{Agradecimentos}

Agradecimento ao SAE/Unicamp pelo financiamento dessa pesquisa.

\footnotetext{
1 ARRETCHE, Marta. "Estado e Mercado na Provisão Habitacional" (1990) 2 ROYER, Luciana. ROYER, Luciana. "Financeirização da política habitacional: limites e perspectivas",
} 